ARTICLE

\title{
Effect of sulfur on sound velocity of liquid iron under Martian core conditions
}

\author{
Keisuke Nishida (iD) ${ }^{1,9 凶}$, Yuki Shibazaki (i) ${ }^{2,3}$, Hidenori Terasaki ${ }^{4}$, Yuji Higo $^{5}$, Akio Suzuki ${ }^{6}$, \\ Nobumasa Funamori ${ }^{7} \&$ Kei Hirose (10) ${ }^{1,8}$
}

Sulfur has been considered to be a predominant light element in the Martian core, and thus the sound velocity of $\mathrm{Fe}-\mathrm{S}$ alloys at relevant high pressure and temperature is of great importance to interpret its seismological data. Here we measured the compressional sound velocity $\left(V_{P}\right)$ of liquid $\mathrm{Fe}, \mathrm{Fe}_{80} \mathrm{~S}_{20}$ and $\mathrm{Fe}_{57} \mathrm{~S}_{43}$ using ultrasonic pulse-echo overlap method combined with a Kawai-type multi-anvil apparatus up to $20 \mathrm{GPa}$, likely corresponding to the condition at the uppermost core of Mars. The results demonstrate that the $V_{P}$ of liquid iron is least sensitive to its sulfur concentration in the Mars' whole core pressure range. The comparison of seismic wave speeds of Fe-S liquids with future observations will therefore tell whether the Martian core is molten and contains impurity elements other than sulfur.

\footnotetext{
${ }^{1}$ Department of Earth and Planetary Science, The University of Tokyo, 7-3-1 Hongo, Bunkyo, Tokyo 113-0033, Japan. ${ }^{2}$ Frontier Research Institute for Interdisciplinary Sciences, Tohoku University, 6-3 Aoba, Aramaki, Aoba, Sendai 980-8578, Japan. ${ }^{3}$ International Center for Young Scientists, National Institute for Materials Science, 1-1 Namiki, Tsukuba, Ibaraki 305-0044, Japan. ${ }^{4}$ Department of Earth and Space Science, Osaka University, 1-1

Machikaneyama-cho, Toyonaka, Osaka 560-0043, Japan. ${ }^{5}$ Japan Synchrotron Radiation Research Institute, 1-1-1 Kouto, Sayo-cho, Sayo, Hyogo 679-5198, Japan. ${ }^{6}$ Department of Earth Science, Tohoku University, 6-3 Aoba, Aramaki, Aoba, Sendai 980-8578, Japan. ${ }^{7}$ Institute of Materials Structure Science, High Energy Accelerator Research Organization (KEK), 1-1 Oho, Tsukuba, Ibaraki 305-0801, Japan. ${ }^{8}$ Earth-Life Science Institute, Tokyo Institute of Technology, $2-$ 12-1 Ookayama, Meguro, Tokyo 152-8550, Japan. ${ }^{9}$ Present address: Bayerisches Geoinstitut, University of Bayreuth, 95440 Bayreuth, Germany.

凶email: Keisuke.Nishida@uni-bayreuth.de
} 
T he Mars is the best studied planet except our own, but its interior remains largely unknown because seismological observations have not been performed yet. Geodesy studies indicated that the Mars has a liquid core ${ }^{1,2}$. The InSight mission is now in progress and has already revealed that Mars is seismically active ${ }^{3}$. Seismological observations are expected to reveal whether the core is fully molten, partially molten, or solid, and to constrain the composition of the core.

The Martian core has been thought to consist of Fe-S alloy because Mars is a volatile-rich planet ${ }^{4}$ and Martian meteorites are depleted in chalcophile elements ${ }^{5}$. For the interpretation of seismic wave speeds, the knowledge of $V_{\mathrm{P}}$ of liquid $\mathrm{Fe}-\mathrm{S}$ alloy as functions of pressure, temperature, and sulfur concentration is necessary. However, previous measurements were made only up to $8 \mathrm{GPa}^{6,7}$ with high precision in a multi-anvil press, much lower than the likely pressure range of the Martian core $(\sim 20$ to $\sim 40$ $\mathrm{GPa})^{2,8}$.

In this study, we determined the $V_{\mathrm{P}}$ of liquid $\mathrm{Fe}, \mathrm{Fe}_{80} \mathrm{~S}_{20}$ and $\mathrm{Fe}_{57} \mathrm{~S}_{43}$ up to $20 \mathrm{GPa}$, likely corresponding to the pressure $(P)$ at the uppermost core of $\mathrm{Mars}^{2,8}$. The $P-V_{\mathrm{P}}$ data obtained are extrapolated to conditions at the center of the Mars $(\sim 40 \mathrm{GPa})^{2,8}$ based on thermodynamical equation of state. We found that sulfur have little effect on the $V_{\mathrm{P}}$ of liquid iron in the Mars' whole core pressure range as opposite to the case for the core of the Moon $(\sim 5 \mathrm{GPa})^{6}$. It is therefore difficult to estimate sulfur content of Martian core based only on velocity even though the Martian core is molten and its seismic velocity will be determined. Alternatively, if the seismic velocity deviates from the values we obtained here, it indicates the presence of considerable amounts of impurity elements other than sulfur.

\section{Results and discussion}

Sound velocity of liquid Fe-S. We measured the $V_{\mathrm{P}}$ of liquid $\mathrm{Fe}, \mathrm{Fe}_{80} \mathrm{~S}_{20}$ and $\mathrm{Fe}_{57} \mathrm{~S}_{43}$ based on ultrasonic pulse-echo method in a Kawai-type multi-anvil press up to $20 \mathrm{GPa}$ at the SPring- 8 and KEK-PF synchrotron radiation facilities in Japan (Fig. 1, Supplementary Fig. 1 and Supplementary Table 1). Temperature effect on the $V_{\mathrm{P}}$ is found to be smaller than experimental uncertainty and is regarded negligible in this study. The velocity decreases with increasing sulfur concentration at low pressure range (Fig. 2a). Nevertheless, pressure effect is larger for $\mathrm{Fe}-\mathrm{S}$ alloys than for pure $\mathrm{Fe}$, and the $V_{\mathrm{P}}$ of liquid $\mathrm{Fe}_{80} \mathrm{~S}_{20}$ approaches that of liquid $\mathrm{Fe}$ around $10 \mathrm{GPa}$. Then, the velocity/pressure slope $\left(\mathrm{d} V_{\mathrm{P}} / \mathrm{d} P\right)$ for $\mathrm{Fe}_{80} \mathrm{~S}_{20}$ diminishes and becomes similar to that for pure Fe at higher pressures. The $V_{\mathrm{P}}$ of liquid $\mathrm{Fe}_{57} \mathrm{~S}_{43}$ also approaches those of liquids $\mathrm{Fe}$ and $\mathrm{Fe}_{80} \mathrm{~S}_{20}$ above $20 \mathrm{GPa}$ (Supplementary Note 1, Supplementary Figs. 2 and 3 ).

The high $\mathrm{d} V_{\mathrm{P}} / \mathrm{d} P$ in liquid Fe-S observed below $10 \mathrm{GPa}$ is not found in liquid Fe. Solid FeS-V is known to exhibit anomalous volume contraction, which is attributed to high-spin to low-spin transition below $13 \mathrm{GPa}^{8}$ (Fig. 2b). Liquid FeS is also expected to undergo the spin crossover and indeed exhibits small bulk modulus $K_{0}$ at 1 bar and large pressure derivative $K^{\prime 9,10}$, leading to high $\mathrm{d} V_{\mathrm{p}} / \mathrm{d} P$. It is possible that liquid $\mathrm{Fe}_{80} \mathrm{~S}_{20}$ is an inhomogeneous mixture of a portion with the Fe-like structure and that with the FeS-like one, as is observed in the Se-Te system $^{11,12}$ (Supplementary Note 2). This is supported by a sigmoidal shape of the liquidus curve in the Fe-FeS system observed from 1 bar to $10 \mathrm{GPa}^{13,14}$, which indicates the presence of metastable two-liquid solvus at intermediate compositions (Supplementary Fig. 4a). Above $10 \mathrm{GPa}$, the sigmoidal liquidus curvature disappears, suggesting a nearly ideal solution ${ }^{14}$ (Supplementary Fig. 4b); the structure of liquid $\mathrm{Fe}_{80} \mathrm{~S}_{20}$ becomes homogeneous by $10 \mathrm{GPa}$ due to spin transition in the FeS-like

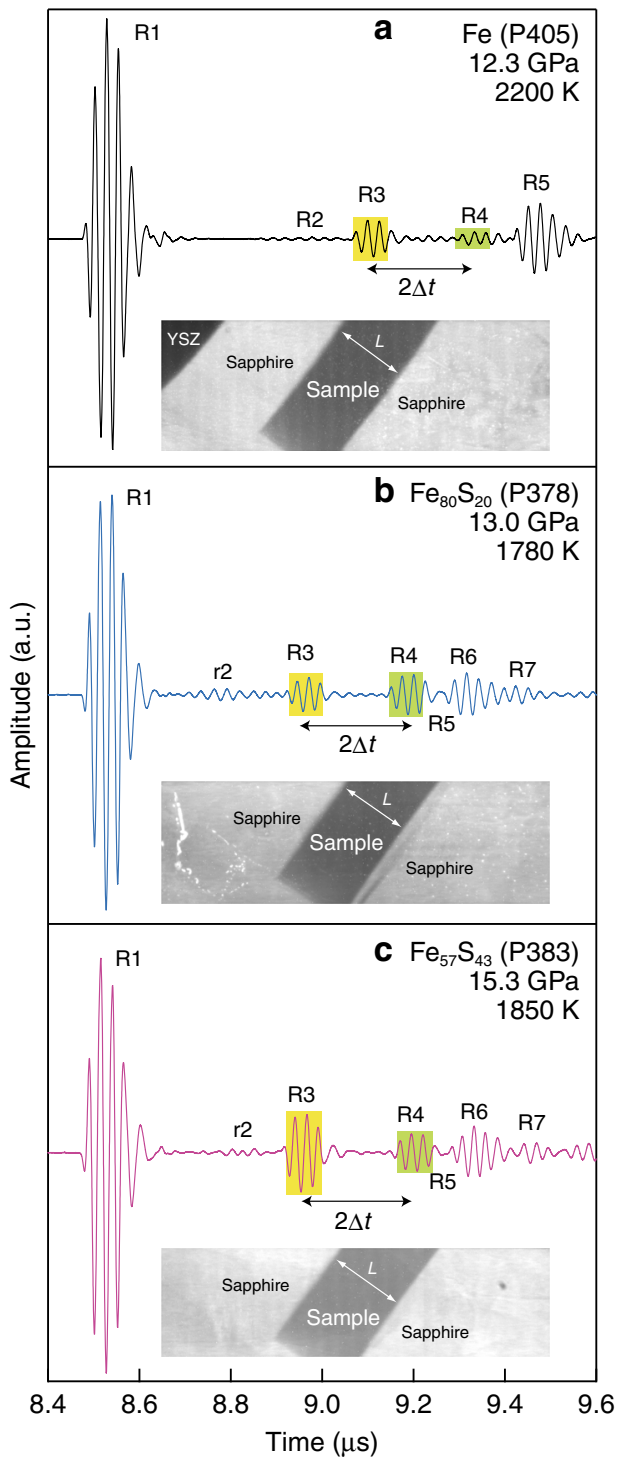

Fig. 1 Examples of ultrasonic waveform and $X$-ray radiographic image of a fully molten sample. (a) $\mathrm{Fe},(\mathbf{b}), \mathrm{Fe}_{80} \mathrm{~S}_{20}$, and (c), $\mathrm{Fe}_{57} \mathrm{~S}_{43}$. R1-R7 represent echo signals by 3 -cycle sine-wave burst with a center frequency of $40 \mathrm{MHz}$ from the following boundaries; R1 = anvil/buffer-rod, R2 = YSZ/ sapphire, $\mathrm{r} 2=\mathrm{ZrO}_{2} / \mathrm{Al}_{2} \mathrm{O}_{3}$ (surroundings), $\mathrm{R} 3=$ fronting sapphire/sample, $\mathrm{R} 4=$ sample/backing sapphire, R5 = sapphire/pressure marker (a) sapphire/c-BN (b, c), R6 =c-BN/pressure marker, R7 = pressure marker/ $\mathrm{MgO}$. See more detail in Supplementary Fig. 7. L in X-ray radiographic image represents sample length; 517.7(5) $\mu \mathrm{m}$ for $\mathrm{Fe}$, 507.7(1) $\mu \mathrm{m}$ for $\mathrm{Fe}_{80} \mathrm{~S}_{20}$ and 541.7(6) $\mu \mathrm{m}$ for $\mathrm{Fe}_{57} \mathrm{~S}_{43}$. $2 \Delta t$ in ultrasonic waveform represents two-way travel time in the sample; $221.1 \mathrm{~ns}$ for $\mathrm{Fe}, 217.0 \mathrm{~ns}$ for $\mathrm{Fe}_{80} \mathrm{~S}_{20}$ and $241.7 \mathrm{~ns}$ for $\mathrm{Fe}_{57} \mathrm{~S}_{43}$. Sound velocity $\left(V_{\mathrm{P}}\right)$ can be obtained as $L / \Delta t$.

portion. This interpretation does not contradict earlier structural studies using X-rays ${ }^{15-18}$.

Implications for Martian core. In order to extrapolate the present $P-V_{\mathrm{P}}$ data to $>40 \mathrm{GPa}$ corresponding to conditions at the center of the Mars ${ }^{2,8}$, we fit adiabatic, third-order finite strain, Birch-Murnaghan equation of state to the data, assuming no temperature dependence (see Methods). Considering the effect of spin crossover in the FeS-like portion in liquid and resulting structural homogenization, only data collected at $\geq 10 \mathrm{GPa}$ and $\geq 6.6 \mathrm{GPa}$ were used for fitting for liquids $\mathrm{Fe}_{80} \mathrm{~S}_{20}$ and $\mathrm{Fe}_{57} \mathrm{~S}_{43}$, respectively. The extrapolations show that the velocities of the 


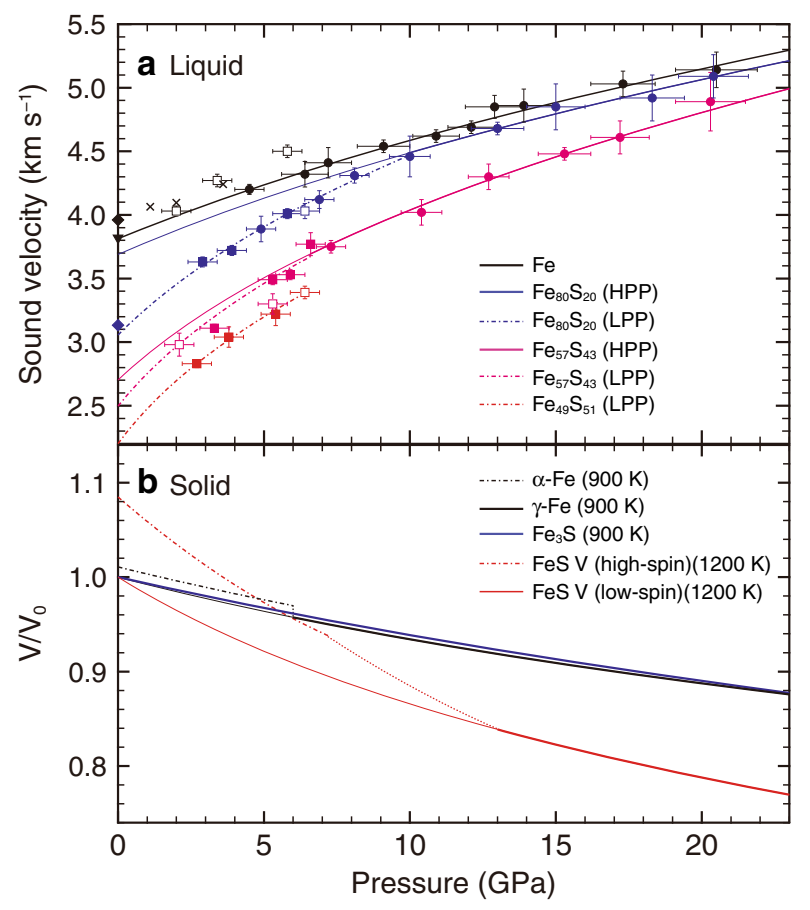

Fig. 2 Sound velocity in liquid Fe and Fe-S alloys and compression curve for solids. a $V_{p}$ data for liquid $\mathrm{Fe}$ (black), $\mathrm{Fe}_{80} \mathrm{~S}_{20}$ (blue), $\mathrm{Fe}_{57} \mathrm{~S}_{43}$ (pink) and $\mathrm{Fe}_{49} \mathrm{~S}_{51}$ (red). Open and solid squares ${ }^{6}$ and crosses $^{7}$ denote ultrasonic $V_{P}$ from previous studies. Solid reverse triangle ${ }^{38}$ and diamonds ${ }^{35,39}$ show 1-bar data. Solid curves denote the best fits for liquid high-pressure phase (HPP) without using shock data. Dash-dotted curves are for low-pressure phase (LPP). b Compression curves of solid $\alpha-\mathrm{Fe}^{40}, \gamma-\mathrm{Fe}^{41}, \mathrm{Fe}_{3} \mathrm{~S}^{42}$, and $\mathrm{FeS} \mathrm{V}^{8}$.

liquid $\mathrm{Fe}-\mathrm{S}$ alloys could be faster than or at least are nearly identical to that of liquid pure $\mathrm{Fe}$ under deep Martian core conditions (Fig. 3). Indeed, our data are consistent with previous first-principles molecular dynamics simulations ${ }^{19-21}$ when extrapolated to Earth's core pressures (Supplementary Fig. 5).

Interestingly the effect of sulfur on the $V_{\mathrm{P}}$ of liquid $\mathrm{Fe}$ is found to be quite minor, just in the Martian core pressure range (Figs. 3 and 4). The model $4,5,22-24$ suggests the bulk Martian core includes $16-36$ at $\% \mathrm{~S}$ (Supplementary Note 3 ). The velocity of liquid $\mathrm{Fe}_{80} \mathrm{~S}_{20}$ overlaps with that of liquid pure $\mathrm{Fe}$ within uncertainty in the whole Martian core pressure range between $\sim 20$ and $\sim 40 \mathrm{GPa}$. A reduction in $V_{\mathrm{P}}$ is only less than $0.3 \%$ per atomic \% S at maximum (between $\mathrm{Fe}_{80} \mathrm{~S}_{20}$ and $\mathrm{Fe}_{57} \mathrm{~S}_{43}$ at 20 GPa) (Fig. 4), unlike the case for the cores of the Earth (>135 $\mathrm{GPa})$ and the Moon $(\sim 5 \mathrm{GPa})^{6}$. The Martian core model ${ }^{2}$ predicted its seismic velocity that is very close to that of liquid $\mathrm{Fe}-\mathrm{S}$ found in this study for Mars' core conditions, suggesting that the travel time curve ${ }^{25}$ calculated for their model ${ }^{2}$ may be observed. However, considering uncertainty in velocity determinations for the Martian core in the near future, the velocity will not tell us its sulfur content. On the other hand, if the seismic velocity is different from the values we obtained here (Fig. 4), it precludes the Fe-FeS binary liquid for Mars' core and alternatively suggests that it contains other impurity element(s). For example, it has been reported ${ }^{26,27}$ that the $V_{\mathrm{P}}$ of liquid $\mathrm{Fe}$ is enhanced by the incorporation of carbon and silicon at 20-40 GPa. They will therefore be alternative candidates for the light element in the Mars' core if higher velocity is obtained. The effects of the other possible light elements such as hydrogen and oxygen remain to be explored at pressures relevant to the Martian core.

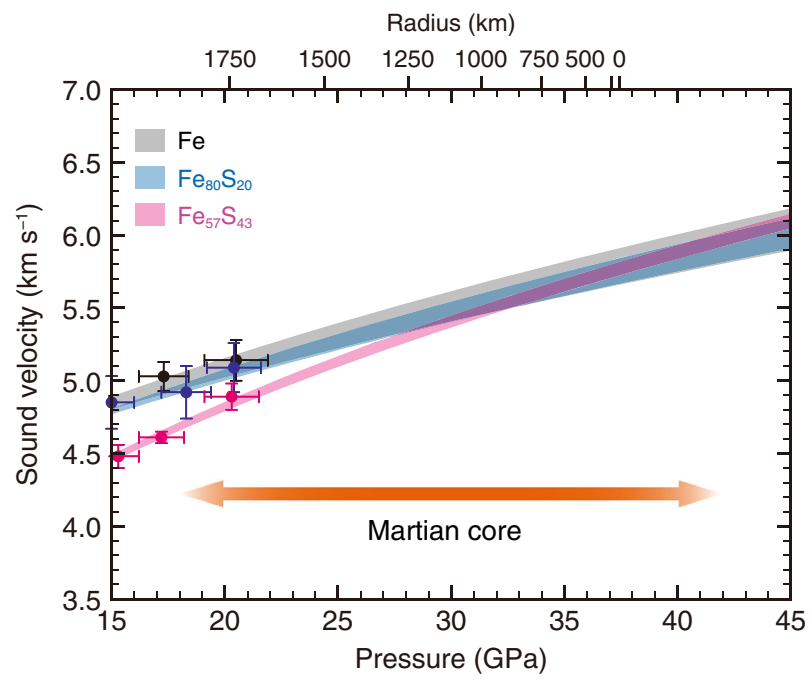

Fig. 3 Pressure effect on $\boldsymbol{V}_{\mathbf{p}}$ in liquid Fe-S under Martian core conditions. Hatched areas denote the ranges of $V_{p}$ in liquid $\mathrm{Fe}$ (gray), $\mathrm{Fe}_{80} \mathrm{~S}_{20}$ (blue) and $\mathrm{Fe}_{57} \mathrm{~S}_{43}$ (pink) extrapolated with and without using shock-wave data. Radius is based on ref. 2 .

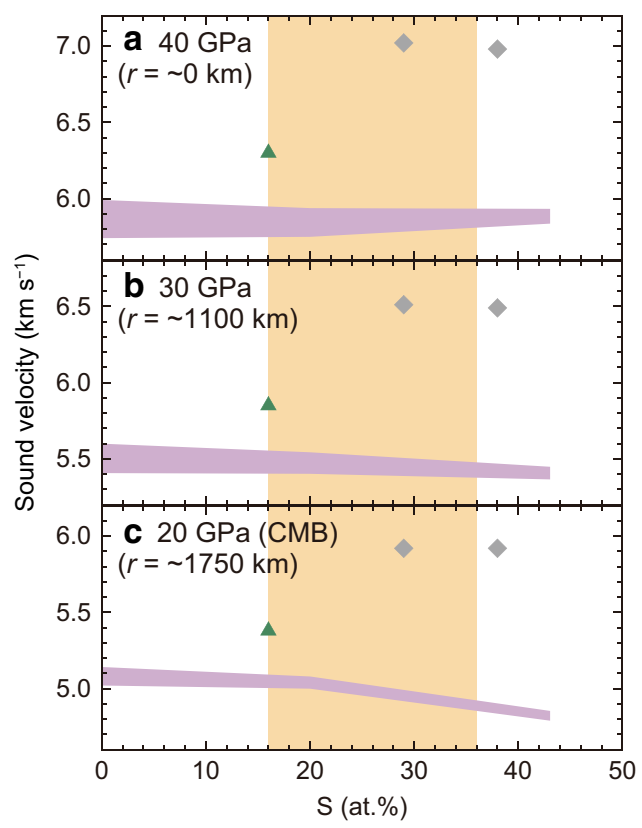

Fig. 4 Sound velocity of liquid Fe-S alloy as a function of sulfur content under Martian core conditions. (a) $40 \mathrm{GPa}$ (Mars' center); (b) $30 \mathrm{GPa}$; (c) $20 \mathrm{GPa}$ (Martian core-mantle boundary). Purple bands show the present estimates. Orange represents the sulfur content expected in the Martian core ${ }^{4,5,22-24}$. Green solid triangles denote $V_{P}$ measured for liquid $\mathrm{Fe}_{84} \mathrm{C}_{16}{ }^{26}$. Gray diamonds denote $V_{\mathrm{P}}$ for $\mathrm{Fe}_{61} \mathrm{Ni}_{10} \mathrm{Si}_{29}$ and $\mathrm{Fe}_{52} \mathrm{Ni}_{10} \mathrm{Si}_{38}$ calculated from ref. 27 . The radius, $r$, is based on ref. 2 .

\section{Methods}

Velocity measurements at high P-T. High-pressure and -temperature $(P-T)$ experiments were conducted using the Kawai-type multi-anvil apparatus MAX-III and SPEED-Mk.II at the beamline AR-NE7A, KEK-PF and at the beamline BL04B1, SPring-8, respectively. The starting materials were pure Fe powder or a powder mixture of $\mathrm{Fe}$ and $\mathrm{FeS}$.

Cell assemblies are shown in Supplementary Fig. 6. We used a cylindrical TiC$\mathrm{Al}_{2} \mathrm{O}_{3}$ composite heater. A semi-sintered $\mathrm{Al}_{2} \mathrm{O}_{3}$ sleeve was used as a thermal insulator. We adopted single-crystal sapphire as a buffer rod and a backing plate with a BN flat-bottomed cylindrical container for liquid Fe-S (type-1 cell assembly). Since chemical reaction between $\mathrm{BN}$ and liquid pure Fe was found in a preliminary experiment (the reaction with liquid $\mathrm{Fe}-\mathrm{S}$ was limited), we also 
employed type- 2 cell assembly, in which sample was surrounded by a single-crystal sapphire sleeve, sintered polycrystalline yttria-stabilized zirconia (YSZ) rod and single-crystal sapphire plate lids (ultrasonic reflectors). Pyrophyllite gaskets were $\mathrm{V}$-grooved $\left(110^{\circ}\right)$ and baked at $973 \mathrm{~K}$ for $30 \mathrm{~min}$. It has been demonstrated ${ }^{28}$ that difference in pressure between a sample fully surrounded by alumina and a pressure marker disappeared above $1073 \mathrm{~K}$. Indeed, the present data for liquid $\mathrm{Fe}_{80} \mathrm{~S}_{20}$ using the type- 1 and type- 2 cell assemblies are consistent with each other.

We used tungsten carbide (WC) anvils with $22 \mathrm{~mm}$ edge lengths as secondstage anvils in MAX-III, and those with 26 and $27 \mathrm{~mm}$ edge length in SPEED-Mk. II. The 22 and $26 \mathrm{~mm}$ WC anvils were made of Tungaloy F grade and employed for experiments at $<15 \mathrm{GPa}$. The $27 \mathrm{~mm}$ ones were made of Fujilloy TF05 grade and used for $>16 \mathrm{GPa}$ experiments. The truncated edge length of the anvil face to a pressure medium was $5 \mathrm{~mm}$.

Sound velocity was obtained by ultrasonic pulse-echo overlap method (Fig. 1 and Supplementary Fig. 7). Longitudinal-wave signals were generated and received by the $36^{\circ} \mathrm{Y}$-cut $\mathrm{LiNbO}_{3}$ transducer. To transfer high amplitude waveform to a sample, non-coated $\mathrm{LiNbO}_{3}$ crystal with diameter of 4 and $5 \mathrm{~mm}$ was mounted onto the opposite corner of WC anvils with $22 \mathrm{~mm}$ and $26 / 27 \mathrm{~mm}$ edge length, respectively. A conducting epoxy layer was placed as an electrode on the $\mathrm{LiNbO}_{3}$ crystal and worked also as a backing material to reduce ringing noise. A three-cycle sine wave burst with frequency of $35-60 \mathrm{MHz}$ was used as an input electrical signal. The echo signal was attenuated and distorted to a large extent when those with $>50$ $\mathrm{MHz}$ were transferred. These phenomena were remarkable, in particular when the $26 / 27 \mathrm{~mm}$ anvils were used. Therefore, the frequency effect on travel time cannot be evaluated quantitatively but is considered to be much smaller than the effects of attenuation and distortion. In contrast, echoes sometimes overlapped with each other when the $35 \mathrm{MHz}$ sine wave burst was transferred. Therefore, the velocities determined at 40 or $45 \mathrm{MHz}$ were employed in this study. Two-way travel time in a sample was obtained by cross correlation function between echoes from the buffer$\mathrm{rod} / \mathrm{sample}$ and sample/backing. Sample length was estimated by an X-ray radiographic image analysis. The error in measured sound velocity was mainly derived from the uncertainty in the sample length.

Energy-dispersive X-ray diffraction (XRD) measurements were performed to obtain sample pressures. We used white X-rays with a Ge-solid state detector at the fixed diffraction angle of $6.0^{\circ}$. Pressure and temperature were determined simultaneously so that a couple of pressure standards (h- $\mathrm{BN}$ and $\mathrm{MgO}$ or $\mathrm{NaCl}$ and $\mathrm{MgO}$ ) give identical pressure ${ }^{29-31}$. A thermocouple was not employed because it causes unwanted deformation of the sample and reduces the accuracy of measurements and could be a source of chemical contamination.

We checked the difference in temperature among pressure marker and several points of the sample position using the type-1 cell assembly, in which sample was replaced by a couple of pressure standards, $\mathrm{NaCl}$ and $\mathrm{MgO}$. Temperatures in a sample chamber ranged from about $30 \mathrm{~K}$ lower to $60 \mathrm{~K}$ higher than that at the usual pressure marker position at $\sim 15 \mathrm{GPa}$ and $\sim 1740 \mathrm{~K}$.

Data acquisition flow is given in Supplementary Fig. 8. Upon each temperature increase by $100-200 \mathrm{~K}$, we first obtained radiographic image and ultrasonic echo signals simultaneously, then XRD data, and collected the radiographic image and ultrasonic signals again. The molten state of a sample was indicated by XRD diffuse signals that are characteristic of liquid. We also employed changes in the radiographic image and ultrasonic signals to identify melting. We kept the molten state of a sample for 1-4 h in total, with data collection time of 7-15 min at each temperature. See Supplementary Fig. 9 for comparison between melting temperatures recognized in the present experiments and those reported in earlier studies.

Chemical analyses of recovered samples. The textures and chemical compositions of recovered samples were examined using a field-emission-type EPMA-WDS (JEOL, JXA-8530F) (Supplementary Tables 1,2). We performed quantitative analyses with $12 \mathrm{kV}$ acceleration voltage and $12 \mathrm{nA}$ beam current using LIF (for $\mathrm{Fe}$ ), PETH (for S) and LDE1 (for O) crystals, employing analytical standards of pure iron, chalcopyrite and hematite. ZAF correction was applied. We used a defocused beam with a diameter of $15 \mu \mathrm{m}$ for the $\mathrm{Fe}_{80} \mathrm{~S}_{20}$ and $\mathrm{Fe}_{57} \mathrm{~S}_{43}$ samples, considering the presence of holes and cracks. For the Fe sample, a focused beam (1 $\mu \mathrm{m})$ was employed. For samples that suffered contamination by $\mathrm{Ti}, \mathrm{C}$ and $\mathrm{Al}$, their concentrations were obtained with a defocused beam $(10 \mu \mathrm{m})$ using PETJ (for Ti), LDE2H (for C) and TAP (Al) crystals employing analytical standards of $\mathrm{TiO}_{2}, \mathrm{Fe}_{3} \mathrm{C}$ and corundum. ZAF correction was also applied.

Supplementary Fig. 10 shows typical back scattered electron images of recovered samples. In experiments with the type-1 assembly, we found no or little dendritic $\mathrm{BN}$ in the quenched liquids $\mathrm{Fe}_{80} \mathrm{~S}_{20}$ and $\mathrm{Fe}_{57} \mathrm{~S}_{43}$. Additionally, while small dendritic oxide crystals were sometimes formed near the buffer rod and the capsule (Supplementary Fig. 10e, f), it should have little affected the $V_{\mathrm{P}}$ measurements because such oxide crystals were very minor and located far from the center of the sample. When adsorbed water was not carefully removed, a large amount of $\mathrm{FeO}$ was observed near the buffer-rod and the capsule. Dendritic B-N-O or B-N-S crystals were also found in the Fe-S matrix uniformly in these experiments. We excluded such experiments from this study.

Contamination by a minor amount of oxygen could have occurred during sample preparation for EPMA analysis, and therefore the oxygen content in a liquid sample may have been smaller. In addition, several recovered samples showed contamination from a TiC- $\mathrm{Al}_{2} \mathrm{O}_{3}$ heater. Radiographic images indicated that the contamination occurred during cooling (i.e. after measuring liquid) in runs \#P393 and \#P404. On the other hand, it is uncertain when it happened in runs \#M2413 and \#M2415. The quantitative EPMA analyses of the Ti, C, Al, and $\mathrm{O}$ contents in quenched liquids are given in Supplementary Table 2 for these two runs. Indeed, the $P-V_{\mathrm{P}}$ curve changes very little with these two data points.

Data extrapolation. $V_{\mathrm{P}}$ of a liquid corresponds to bulk sound velocity and is written as

$$
V_{P}(P, T)=\sqrt{\frac{K_{S}(P, T)}{\rho(P, T)}}
$$

in which $K_{\mathrm{S}}$ is adiabatic bulk modulus. The present measurements show a small temperature effect on $V_{\mathrm{P}}$, and thus;

$$
V_{P}(P, T) \approx V_{P}\left(P, T_{S}\right)=\sqrt{\frac{K_{S}\left(P, T_{S}\right)}{\rho\left(P, T_{S}\right)}}
$$

with $T_{\mathrm{S}}$ of temperature on a reference isentrope. $\rho\left(P, T_{\mathrm{S}}\right)$ and $K_{\mathrm{S}}\left(P, T_{\mathrm{S}}\right)$ can be expressed by the adiabatic third-order Birch-Murnaghan EoS as

$$
\begin{gathered}
P=1.5 K_{S 0}\left(\frac{\rho}{\rho_{0}}\right)^{\frac{5}{3}}\left[\left(\frac{\rho}{\rho_{0}}\right)^{\frac{2}{3}}-1\right]\left[1+0.75\left(K_{S}^{\prime}-4\right)\left\{\left(\frac{\rho}{\rho_{0}}\right)^{\frac{2}{3}}-1\right\}\right] \\
K_{S}=K_{S 0}\left(\frac{\rho}{\rho_{0}}\right)^{\frac{5}{3}}\left[1+0.5\left(3 K_{S}^{\prime}-5\right)\left\{\left(\frac{\rho}{\rho_{0}}\right)^{\frac{2}{3}}-1\right\}+\frac{27}{8}\left(K_{S}^{\prime}-4\right)\left\{\left(\frac{\rho}{\rho_{0}}\right)^{\frac{2}{3}}-1\right\}\right.
\end{gathered}
$$

in which $K_{S}^{\prime}$ is the pressure derivative of $K_{\mathrm{S}}$ and subscript zero indicates values at ambient pressure. We fit Eqs. (2-4) to the present $P-V_{\mathrm{P}}$ data (Fig. 2 and Supplementary Fig. 1). The $P-V_{\mathrm{P}}$ fitting curve is practically independent on the choice of $\rho_{0}$ (Supplementary Fig. 11), while there is a trade-off between $\rho_{0}$ and the combination of $K_{\mathrm{S} 0}$ and $K_{S}^{\prime}$. In other words, when $\rho_{0}$ is unknown, it is difficult to obtain $\rho$ and $K_{\mathrm{S}}$ precisely but is possible to extrapolate $V_{\mathrm{P}}$ to higher pressure.

In the cases of $\mathrm{Fe}_{80} \mathrm{~S}_{20}$ and $\mathrm{Fe}_{57} \mathrm{~S}_{43}$, only the data collected $\geq 10.0 \mathrm{GPa}$ and $\geq 6.6$ $\mathrm{GPa}$ were fitted, respectively, considering the effect of spin crossover in the FeS-like portion in liquids. We also performed fitting to our $P-V_{\mathrm{P}}$ data together with previous shock data on $\mathrm{Fe}^{32}, \mathrm{Fe}_{80} \mathrm{~S}_{20}{ }^{33}$, and $\mathrm{Fe}_{57} \mathrm{~S}_{43}$ (ref. ${ }^{34}$ for $\mathrm{FeS}$ ). Fitting parameters obtained by weighted least-squared fitting are summarized in Supplementary Table 3 . The $K_{\mathrm{S} 0}$ and $K_{S}^{\prime}$ values for liquid Fe obtained together with shock-wave data agree with those reported in earlier studies ${ }^{35,36}$. The reference density for liquid Fe-S should be the one for the high-pressure structure where spin transition is complete. Here we chose the $\rho_{0}$ values for liquids $\mathrm{Fe}_{80} \mathrm{~S}_{20}$ and $\mathrm{Fe}_{57} \mathrm{~S}_{43}$, which explain the $P-\rho$ data obtained by shock experiments ${ }^{33}$. Such $\rho_{0}$ for liquid $\mathrm{Fe}_{80} \mathrm{~S}_{20}$ is, however, not consistent with the other $P-\rho$ relations by theory ${ }^{21}$ and experiments ${ }^{37}$. Therefore, the $\rho_{0}, K_{\mathrm{S} 0}$ and $K_{\mathrm{S}}{ }^{\prime}$ for liquids $\mathrm{Fe}_{80} \mathrm{~S}_{20}$ and $\mathrm{Fe}_{57} \mathrm{~S}_{43}$ listed in Supplementary Table 3 are not certain.

As shown in Supplementary Fig. 1, the fitting curves reproduce the experimental data well. There is no significant difference between those with and without considering the shock-wave data in the present experimental pressure range. In the Earth's core pressure range (>135 GPa), the extrapolated $V_{\mathrm{P}}$ of liquids $\mathrm{Fe}$ and $\mathrm{Fe}_{80} \mathrm{~S}_{20}$ without shock data is slightly higher than that considering them but matches the results by first-principles molecular dynamics simulations ${ }^{19-21}$ (Supplementary Fig. 3).

The present $P-T$ conditions of measuring the velocity of liquid $\mathrm{Fe}_{80} \mathrm{~S}_{20}$ are illustrated in Supplementary Fig. 12. While temperature ranged from 1700 to 2240 $\mathrm{K}$, we obtain a single $P-V_{\mathrm{P}}$ relation (Fig. 2), indicating that $V_{\mathrm{P}}$ is insensitive to temperature. Our data may be applicable to the Martian core without correcting for a temperature difference.

\section{Data availability}

The data supporting the main findings of this study are available in the paper and its Supplementary Information. Any additional data can be available from the corresponding author upon reasonable request.

Received: 7 October 2019; Accepted: 20 March 2020; Published online: 13 May 2020

\section{References}

1. Yoder, C. F., Konopliv, A. S., Yuan, D. N., Standish, E. M. \& Folkner, W. M. Fluid core size of Mars from detection of the solar tide. Science 300, 299-303 (2003). 
2. Rivoldini, A., Van Hoolst, T., Verhoeven, O., Mocquet, A. \& Dehant, V. Geodesy constraints on the interior structure and composition of Mars. Icarus 213, 451-472 (2011)

3. Giardini, D. et al. The seismicity of Mars. Nat. Geosci. 13, 205-212 (2020).

4. Taylor, G. J. The bulk composition of Mars. Chem. Erde 73, 401-420 (2013).

5. Dreibus, G. \& Wänke, H. Mars, a volatile-rich planet. Meteoritics 20, 367-381 (1985).

6. Nishida, K. et al. Towards a consensus on the pressure and composition dependence of sound velocity in the liquid Fe-S system. Phys. Earth Planet. Inter. 257, 230-239 (2016).

7. Jing, Z. et al. Sound velocity of $\mathrm{Fe}-\mathrm{S}$ liquids at high pressure: implications for the Moon's molten outer core. Earth Planet. Sci. Lett. 396, 78-87 (2014).

8. Urakawa, S. et al. Phase relationships and equations of state for FeS at high pressures temperatures and implications for the internal structure of Mars. Phys. Earth Planet. Inter. 143-144, 469-479 (2004).

9. Nishida, K. et al. Density measurement of liquid FeS at high pressures using synchrotron X-ray absorption. Am. Mineral. 96, 864-868 (2011).

10. Chen, J., Yu, T., Huang, S., Girard, J. \& Liu, X. Compressibility of liquid FeS measured using X-ray radiograph imaging. Phys. Earth Planet. Inter. 228, 294-299 (2014).

11. Takimoto, K. \& Endo, H. Sound velocity of liquid Se-Te mixture. Phys. Chem. Liq. 12, 141-150 (1982).

12. Kajihara, Y. et al. Static and dynamical inhomogeneity at liquid-liquid phase transition of Se-Te mixtures. EPJ Web Conf. 15, 02002 (2011)

13. Guillermet, A. F., Hillert, M., Jansson, B. \& Sundman, B. An assessment of the $\mathrm{Fe}-\mathrm{S}$ system using a two-sublattice model for the liquid phase. Metall. Trans. B 12, 745-754 (1981).

14. Buono, A. S. \& Walker, D. The Fe-rich liquidus in the Fe-FeS system from 1bar to $10 \mathrm{GPa}$. Geochim. Cosmochim. Acta 75, 2072-2087 (2011).

15. Sanloup, C., Guyot, F., Gillet, P. \& Fei, Y. Physical properties of liquid Fe alloys at high pressure and their bearings on the nature of metallic planetary cores. J. Geophys. Res. Solid Earth 107, 2272 (2002).

16. Shibazaki, Y. \& Kono, Y. Effect of silicon, carbon, and sulfur on structure of liquid iron and implications for structure-property relations in liquid ironlight element alloys. J. Geophys. Res. Solid Earth 123, 4697-4706 (2018).

17. Morard, G. et al. Structure of eutectic Fe-FeS melts to pressures up to $17 \mathrm{GPa}$ : Implications for planetary cores. Earth Planet. Sci. Lett. 263, 128-139 (2007).

18. Morard, G. et al. In situ determination of $\mathrm{Fe}-\mathrm{Fe}_{3} \mathrm{~S}$ phase diagram and liquid structural properties up to 65 GPa. Earth Planet. Sci. Lett. 272, 620-626 (2008).

19. Marqués, M., González, L. E. \& González, D. J. Pressure-induced changes in structural and dynamic properties of liquid Fe close to the melting line. An ab initio study. J. Phys. Condens. Matter 28, 075101 (2016).

20. Ichikawa, H., Tsuchiya, T. \& Tange, Y. The P-V-T equation of state and thermodynamic properties of liquid iron. J. Geophys. Res. Solid Earth 119, 240-252 (2014).

21. Umemoto, K. et al. Liquid iron-sulfur alloys at outer core conditions by firstprinciples calculations. Geophys. Res. Lett. 41, 6712-6717 (2014)

22. Lodders, K. \& Fegley, B. Jr. An oxygen isotope model for the composition of Mars. Icarus 126, 373-394 (1997).

23. Sanloup, C., Jambon, A. \& Gillet, P. A simple chondritic model of Mars. Phys. Earth Planet. Int. 112, 43-54 (1999).

24. Khan, A. \& Connolly, J. A. D. Constraining the composition and thermal state of Mars from inversion of geophysical data. J. Geophys. Res. 113, E07003 (2008)

25. Helffrich, G. Mars core structure-concise review and anticipated insights from InSight. Prog. Earth Planet Sci. 4, 24 (2017).

26. Nakajima, Y. et al. Carbon-depleted outer core revealed by sound velocity measurements of liquid iron-carbon alloy. Nat. Commun. 6, 8942 (2015).

27. Terasaki, H. et al. Pressure and composition effects on sound velocity and density of core-forming liquids: Implication to core compositions of terrestrial planets. J. Geophys. Res. Planets 124, 2272-2293 (2019).

28. Nishida, K., Terasaki, H., Suzuki, A. \& Ohtani, H. The effect of sulfur content on density of the liquid Fe-S at high pressure. Phys. Chem. Miner. 35, 417-423 (2008).

29. Wakabayashi, D. \& Funamori, N. Solving the problem of inconsistency in the reported equations of state for h-BN. High. Press. Res. 35, 123-129 (2015)

30. Tange, Y., Nishihara, Y. \& Tsuchiya, T. Unified analyses for P-V-T equation of state of MgO: a solution for pressure-scale problems in high $\mathrm{P}-\mathrm{T}$ experiments. J. Geophys. Res. 114, B03208 (2009).

31. Decker, D. L. High-pressure equation of state for $\mathrm{NaCl}, \mathrm{KCl}$, and CsCl. J. Appl. Phys. 42, 3239-3244 (1971).

32. Nguyen, J. H. \& Holmes, N. C. Melting of iron at the physical conditions of the Earth's core. Nature 427, 339-342 (2004).

33. Huang, $\mathrm{H}$. et al. Measurements of sound velocity of liquid $\mathrm{Fe}-11.8$ wt \% S up to $211.4 \mathrm{GPa}$ and 6,150 K. J. Geophys. Res. Solid Earth 123, 4730-4739 (2018).
34. Shaner, J. W., Hixson, R. S., Winkler, M. A., Boness, D. A. \& Brown, J. M. in Shock Waves in Condensed Matter (eds Schmidt, S.C. \& Holmes, N.C.) 135-138 (Elsevier, 1988).

35. Nasch, P. M. \& Manghnani, M. H. in Properties of Earth and Planetary Materials at High Pressure and Temperature (eds Manghnani, M. H. \& Yagi, T.) 307-317 (AGU, 1998).

36. Anderson, W. W. \& Ahrens, T. J. An equation of state for liquid iron and implications for the Earth's core. J. Geophys. Res. 99, 4273-4284 (1994).

37. Morard, G. et al. The Earth's core composition from high pressure density measurements of liquid iron alloys. Earth Planet. Sci. Lett. 373, 169-178 (2013).

38. Nasch, P. M., Manghnani, M. H. \& Secco, R. A. Sound velocity measurements in liquid iron by ultrasonic interferometry. J. Geophys. Res. 99, 4285-4291 (1994).

39. Nasch, P. M., Manghnani, M. H. \& Secco, R. A. Anomalous behavior of sound velocity and attenuation in liquid Fe-Ni-S. Science 277, 219-221 (1997).

40. Zhang, J. \& Guyot, F. Thermal equation of state of iron and $\mathrm{Fe}_{0.91} \mathrm{Si}_{0.09}$. Phys. Chem. Miner. 26, 206-211 (1999).

41. Tsujino, N. et al. Equation of state of $\gamma$-Fe: reference density for planetary cores. Earth Planet. Sci. Lett. 375, 244-253 (2013).

42. Chen, B., Gao, L., Funakoshi, K. \& Li, J. Thermal expansion of iron-rich alloys and implications for the Earth's core. Proc. Natl Acad. Sci. USA 104, 9162-9167 (2007).

\section{Acknowledgements}

The authors acknowledge K. Ichimura, H. Yoshida and K. Yonemitsu for assisting EPMA analyses. We also thank Y. Tange, S. Kamada, H. Tobe, R. Abe, S. Kobayashi, I. Yamada, Y. Shimoyama, and K. Watanabe for their advice and technical support. Comments from anonymous reviewers helped to improve the manuscript. This work was supported by JSPS KAKENHI (grant no. 12J07930, 26800231, 17K14379, and 16H06285). The synchrotron radiation experiments were performed at the BL04B1 beamline at the SPring- 8 facility (proposal no. 2013A1508, 2013B1174, 2014A1146, 2016A1235, 2017A1255, and 2017B1270) and at the AR-NE7A beamline at the KEK PF-AR facility (proposal no. 2015G539 and 2017G634).

\section{Author contributions}

K.N. organized the research project and carried out most of the experiments and data analyses with help by Y.S., H.T., A.S. and Y.H. All authors discussed experimental results and their geophysical implications. The manuscript was written by K.N., N.F., and K.H.

\section{Competing interests}

The authors declare no competing interests.

\section{Additional information}

Supplementary information is available for this paper at https://doi.org/10.1038/s41467 020-15755-2.

Correspondence and requests for materials should be addressed to K.N.

Peer review information Nature Communications thanks the anonymous reviewer(s) for their contribution to the peer review of this work. Peer reviewer reports are available.

Reprints and permission information is available at http://www.nature.com/reprints

Publisher's note Springer Nature remains neutral with regard to jurisdictional claims in published maps and institutional affiliations.

Open Access This article is licensed under a Creative Commons Attribution 4.0 International License, which permits use, sharing, adaptation, distribution and reproduction in any medium or format, as long as you give appropriate credit to the original author(s) and the source, provide a link to the Creative Commons license, and indicate if changes were made. The images or other third party material in this article are included in the article's Creative Commons license, unless indicated otherwise in a credit line to the material. If material is not included in the article's Creative Commons license and your intended use is not permitted by statutory regulation or exceeds the permitted use, you will need to obtain permission directly from the copyright holder. To view a copy of this license, visit http://creativecommons.org/ licenses/by/4.0/

(C) The Author(s) 2020 